\title{
Differences in responses to light between two species of planaria: Dugesis tigrina and D. dorotocephala
}

\author{
R. C. DeBold, W. R. Thompson and C. Landraitis \\ WESLEYAN UNIVERSITY
}

\begin{abstract}
Twenty planaria of each of two species were run in a light-dark apparatus. In addition to morphological differences between the two species, there were found to be highly significant differences between the species on the percentage of time spent in the light. Two measures were used with parallel results.

Problem
\end{abstract}

The report by Thompson \& McConnell (1955) of classical conditioning in the planarian has led to wide interest in the behavior of this primitive invertebrate. The possibility of the demonstration of learning in a relatively simple animal creates excitement because of the possibility that new techniques of observation may permit the analysis of the structural or chemical changes involved in learning (Jensen, 1964).

The usual conditioning procedure for planaria involves a light as CS and a shock as US. But Halas et al. (1961, 1962) report that light and shock produce behaviors of a similar topography in the planarian (cf Walter, 1907).

The present experiment was performed after the authors noticed, while attempting to replicate Thompson \& McConnell, that different species of planaria respond differently to light. The species of planaria were compared on the amount of time spent in the dark half of a light-dark apparatus. In addition, rate of swimming, morphology and clinging behavior were observed. Method

Dugesia tigrina were obtained from the Connecticut Valley Biological Supply Company. The Dugesia dorotocephala were obtained from the General Biological Supply Company. Twenty worms of each species were chosen on the basis of size and appearance. Normal appearing, healthy worms of about 1.2 to $1.7 \mathrm{~cm}$ in length were used. In general, the Dugesia dorotocephala are larger at maturity than Dugesia tigrina and therefore size matching may result in a different maturity level between species, i. e., the Dugesia tigrina may have been less mature animals. We did not control this factor.

The test apparatus was a solid plexiglass block which contained four V-shaped grooves, $1 / 2$ in deep and 4 in long. The grooves were filled with spring water. Half of each groove was shielded from a 16-w fluorescent light bulb suspended 18 in above the block. No attempt was made to prevent light diffusion through the block.
The room was dark except for the fluorescent bulb. Testing began at $2 \mathrm{pm}$ on both days of the experiment. Room temperature was 67-71 degrees. The planarian had not been fed for three days prior to the first day of the experiment.

Shortly before they were tested, the worms were transferred to $41 / 2$ in diameter glass bowls to adapt them to a change in water. The water in the bowls was drawn from the same supply from which the apparatus was filled. Just before testing, each worm was placed individually for $2 \mathrm{~min}$. in a small watch-glass of the same water, under the light, next to the test apparatus to insure that the worm was not dormant and to minimize possible effects of a sudden change in light intensity just prior to testing.

Two worms from each species were placed in the apparatus at a time, one worm to a groove. The four worms run at the same time constituted a squad. The worms were placed at the extreme end of the lighted half of a groove. The grooves used for each species were changed for each squad to control minor differences in the grooves. The water was not changed between squads.

Each squad of four worms spent $20 \mathrm{~min}$. in the apparatus. A stopwatch was started when a worm was placed in the apparatus and each passage of an animal across the center of the groove from light to dark or dark to light was recorded.

\section{Results and Diseussion}

Both species were photo-negative under the conditions of the experiment. The dorotocephala spent a mean of $40 \%$ of the $20 \mathrm{~min}$. in light, while the tigrina spent a mean of $19 \%$ in light (see Fig. 1). This is a very significant difference between the two species. In a composite-rank test for unpaired observations (Wilcoxon, 1949), $\Sigma \mathrm{R}_{\mathrm{S}}=261.5 ; \mathrm{p}<.01 ; \mathrm{N}=20$.

At the start of the experiment, the worms swam from the lighted end of the grooves toward the division points. To eliminate a possible bias due to species differences in swimming speed, a second analysis of the data was made, beginning at the time the worm first reached the dividing point between light and dark. The time from first entering the dark until last entering the dark was computed. This procedure eliminated the first leg behavior of slow starters and the last leg behavior of worms which entered the dark and remained there. 
The time spent in the light during this period was divided by the total length of time in this reduced period. Again, the tigrina were significantly more photonegative $\left(\Sigma \mathrm{R}_{\mathrm{S}}=302 ; \mathrm{p}<.01\right)$.

Dorotocephala spent the full $20 \mathrm{~min}$. swimming end to end in the groove in a very regular fashion, only occasionally turning before reaching the end. Nevertheless, 17 of the 20 dorotocephala spent more time in the dark. If the distance covered was equal, this may indicate that dorotocephala swim faster in light, i. e., they show a photokinetic response.

The tigrina were much less regular in their swimming. They tended to cease swimming for long periods during the test, always in the dark part of the apparatus. This may indicate a negative photo-tropism, i. e., actual avoidance of light, or it may indicate a photo-kinesis like that of dorotocephala, except that the animals actually cease swimming in the dark. The data do not allow a determination of light-dark differences in swimming speed for tigrina.

Morphologically, unselected dorotocephala are larger and darker in color than tigrina. The difference in color may result in differences in light absorption and possible activation due to temperature change, or some other energizing effect. The eye-spots of these worms are not image-forming, and there are no obvious differences between the species in the morphology of the eye-spots.

If the worms were placed in a smooth glass bowl and the water swirled, the tigrina appeared to cling more strongly to the surface and resist being swept away better than dorotocephala. No exact tests were made of this effect, but these general observations suggest that the locomotion technique of tigrina may differ enough from that of dorotocephala to account for the results.

Our results suggest that the two species of worms cannot be used interchangeably in experiments in which light is the conditioned stimulus. Further, they suggest that the use of a light CS and a shock UCS is an inadvisable conditioning paradigm, since planaria are photo-negative and therefore, the CS is not neutral prior to the experiment (Jensen, 1964). Conditioned responses obtained in such a paradigm may be the result

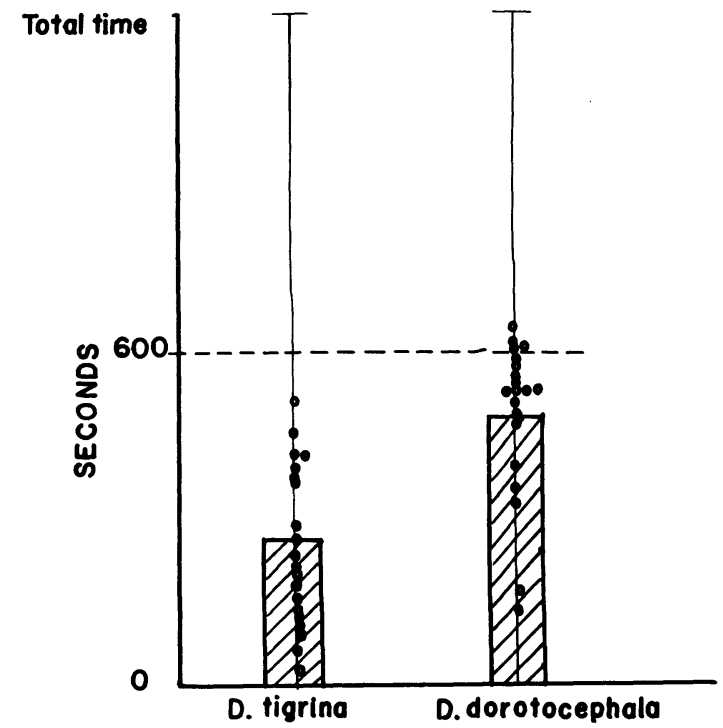

Fig. 1. Total time spent in the lighted half of the apparatus. Each dot indicates an individual score. The bars indicate the group average time spent in light.

of an unlearned tendency to respond to the light plus the effect of pairing of the CS and UCS. Interpretation of the results of such experiments as learning is thrown into doubt.

\section{References}

HALAS, E. S., JAMES, R. L., \& KNUTSON, C. S. An attempt at classical conditioning in the planarian. J. comp. physiol. Psychol., 1962, 55, 969-971.

HALAS, E. S., JAMES, R. L., \& STONE, L. H. Types of responses elicited in planaria by light. J. comp. physiol. Psychol., 1961, $54,302-305$.

JENSEN, D. D. Paramecia, planaria and pseudolearning. A paper presented at Cambridge University, England, 7 July 1964.

THOMPSON, R., \& McCONNELL, J. Classical conditioning in the planarian Dugesia dorotocephala. J. comp. physiol. Psychol., 1955, 48, 65-68.

WALTER, H. The reactions of planaria to light. J. exp. Zool., 1907, 5, 35-162.

WILCOXON, F. Some rapid approximate statistical procedures. Stamford, Conn.: American Cyanamid Co., 1949.

\section{Note}

The research reported in this paper was supported by Grant MH8740 to the first author by the U. S. Public Health Service and Grant NSF GB-2490 to the second author by the National Science Foundation. 